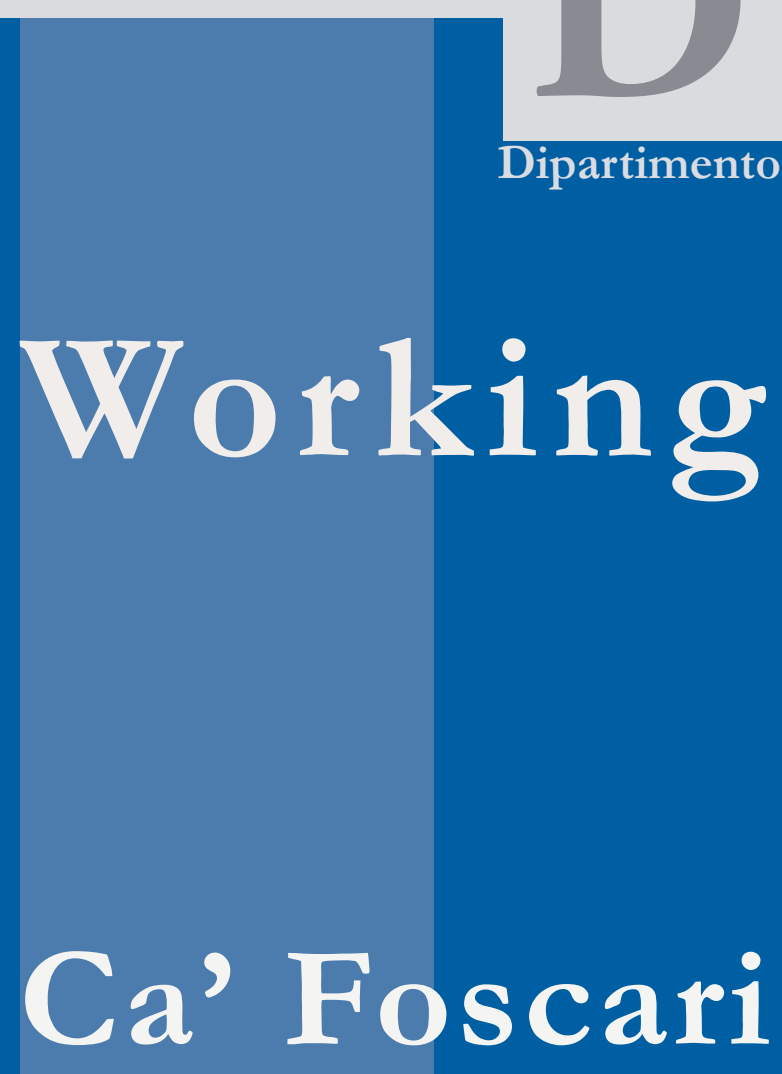

Paper

Department

of Economics

University of

Venice

Roberto Roson

Dominique van der Mensbrugghe

Climate Change and Economic

Growth: Impacts and Interactions 


\title{
Climate Change and Economic Growth: Impacts and Interactions
}

\author{
Roberto Roson \\ Cà Foscari University, Venice, IEFE and CMCC \\ Dominique van der Mensbrugghe \\ DECPG, The World Bank, Washington
}

First Draft: April 2010

\begin{abstract}
An integrated assessment model (ENVISAGE), including a CGE-based economic module and a climate module, is used to assess the effects of a variety of economic impacts induced by climate change. These impacts include: sea level rise, variations in crop yields, water availability, human health, tourism, energy demand. Two scenarios are compared: a baseline growth path, disregarding any climate change effect, and a counterfactual case, accounting for the impacts. The model assesses the overall magnitude of the impacts, their regional distribution, and the contribution of each specific impact to the overall variation of income and welfare. Results (e.g., on real GDP) show that climate change impacts are substantial, especially for developing countries and in the long run.
\end{abstract}

Keywords

Climate Change, Integrated Assessment, Dynamic General Equilibrium.

JEL Codes

C68, D58, F43, F47, Q54, Q56

Address for correspondence:

Roberto Roson

Department of Economics Ca' Foscari University of Venice Cannaregio 873, Fondamenta S.Giobbe 30121 Venezia - Italy

Phone: (++39) 0412349147

Fax: (++39) 0412349176 e-mail: roson@unive.it

This Working Paper is published under the auspices of the Department of Economics of the Ca' Foscari University of Venice. Opinions expressed herein are those of the authors and not those of the Department. The Working Paper series is designed to divulge preliminary or incomplete work, circulated to favour discussion and comments. Citation of this paper should consider its provisional character.

Department of Economic

Ca' Foscari University of Venice

Cannaregio 873, Fondamenta San Giobbe

30121 Venice Italy

Fax: ++390412349210 


\section{Introduction}

Understanding the climate change impacts on the world economy is, obviously, of paramount importance for both climate change mitigation and adaptation policies. Modelling climate impacts, however, is a quite hard enterprise, for two main reasons.

First, climate change is a systemic phenomenon, both in terms of natural and human systems. In the so-called "Earth System", physical elements like the oceans, winds, the stratosphere, etc., interact in the determination of global climate conditions. In terms of socio-economic consequences, market linkages and trade propagate the effects of noneconomic factors throughout the globalized economy. As climate change is an intrinsically systemic phenomenon, it is inherently affected by complexity and uncertainty.

Second, socio-economic impacts of climate change have different dimensions (e.g., sea level rise, human health, etc.), each one with different mechanisms and implications. To achieve a realistic assessment of the impacts, there is a need to separately and adequately address each dimension.

A number of numerical Integrated Assessment Models have considered and quantified climate change impacts (for a review, see Stern, 2007, chapter 6). However, most of these models rely on aggregate modelling, sometimes with only one good produced and consumed in each regional economy and no international trade.

A much more limited number of models embody a computable general equilibrium structure, allowing them to consider variations in the economic structure, secondary effects and changes in the terms of trade. These models also allow to more specifically consider the sector-specific impacts of climate change.

One of the early examples in this direction is the DART model by Deke et al. (2001), where a CGE model is used to assess the impact of climate change induced changes in agricultural productivity and sea level rise. Bosello, Roson and Tol (2006, 2007), Berrittella et al. (2006) have also used comparative static CGE models to quantify specific effects of the climate change.

In a recent paper, Eboli, Parrado and Roson (2009) use a dynamic computable general equilibrium model (ICES), to assess the economic consequences of climate change impacts. They use a set of sectoral impact estimates, derived from previous studies and adapted to the structure of the CGE model, to simulate and compare two scenarios, with and without climate change impacts. They find (in line with Dell et al., 2008) that macroeconomic effects are sizeable but, most importantly, that there are significant distributional effects at the regional and industrial level.

This study adopts a similar approach, but innovates by considering more climate change impacts, by improving parameter estimates and by using a more sophisticated model, 
named ENVISAGE, developed at the World Bank. ${ }^{1}$ Even in this case, two scenarios (with and without impacts) are simulated and assessed, and the overall results are compared with those obtained with the ICES model.

The structure of the ENVISAGE model will be briefly illustrated in the next section. Estimation of climate change impact parameters is discussed in section 3, whereas results are presented and commented in section 4 . Some concluding remarks follow.

\section{The ENVISAGE model structure}

The results in this paper rely on the World Bank's Environmental Impact and Sustainability Applied General Equilibrium (ENVISAGE) Model. ${ }^{2}$ The ENVISAGE model's core is a relatively standard recursive dynamic global general equilibrium (CGE) model. Incorporated with the core CGE model is a greenhouse gas (GHG) emissions module that is connected to a simple climate module that converts emissions into atmospheric concentrations, radiative forcing and changes in mean global temperature. The climate module has feedback on the economic model through so-called damage functions, affecting a number of parameters in the model, as explained in more detail in the next section. The combination of the socio-economic CGE model with the climate module is commonly referred to an integrated assessment model (IAM).

ENVISAGE is calibrated to Release 7.1 of the GTAP dataset with a 2004 base year. ${ }^{3}$ It has been used to simulate dynamic scenarios through 2100 . The 112 countries/regions and 57 sectors of GTAP are aggregated to a smaller set of countries/regions and sectors to facilitate computing. The GTAP data is supplemented with satellite accounts that include emissions of the so-called Kyoto gases - carbon dioxide $\left(\mathrm{CO}_{2}\right)$, methane $\left(\mathrm{CH}_{4}\right)$, nitrous oxide $\left(\mathrm{N}_{2} \mathrm{O}\right)$ and hydrofluorocarbons (F-gases), different electricity production activities (coal, oil and gas, hydro, nuclear and other), and potential land and hydro supplies.

Within each time period a full equilibrium is achieved given the fixed regional endowments, technology and consumer preferences. Production is modeled as a series of nested constant-elasticity-of-substitution (CES) functions that are designed to reflect the substitution and complementarity of inputs. Unlike many standard models, energy plays a key role as an input and is modeled as a complement to capital in the short-run but a substitute to capital in the long run. This reflects the putty/clay specification of production that incorporates vintage capital. The key assumption is that there is greater substitution across inputs in the long run (i.e. with new capital) than in the short run (with

\footnotetext{
${ }^{1}$ ENVISAGE is technically superior to the ICES model. It includes a climate module, so that climate change is endogenous, whereas ICES relies on exogenously given climate scenarios. It distinguishes between old (installed) and new capital stock, which allows considering different degrees of capital mobility. It also includes a fully-fledged consumption demand system, which is important to account for differences in income elasticity and structural changes in demand patterns, especially relevant in the long run.

${ }^{2}$ See van der Mensbrugghe 2008 for full details of the model.

${ }^{3}$ See www.gtap.org.
} 
old or installed) capital. One consequence of this specification is that countries that have higher growth and higher rates of investment typically have a more flexible economy in the aggregate. There is a single representative household that consumes goods and services and saves. ${ }^{4}$ The savings rate is partially a function of the demographic structure of the region. Savings rise as either the elderly or youth dependency ratios fall. The government sector is relatively passive. Aggregate expenditures are fixed as a share of total GDP and revenues adjust to maintain fiscal balance (through a lump sum tax on households). Investment is savings driven.

Aggregate demand by sector is summed across all domestic agents and represents a composite of domestically produced goods and imports - the so-called Armington aggregate. ${ }^{5}$ The aggregate Armington good is allocated between domestic production and imports using a two-nested CES specification. The first nest allocates aggregate demand between domestic production and an aggregate import bundle. The second nest decomposes aggregate imports into import by region of origin. This generates a bilateral trade flow matrix. Domestic producers are assumed to supply both domestic and export markets without friction, i.e. the law of one price holds for domestically produced goods irrespective of their final destination. ${ }^{6}$ Bilateral trade is associated with three price wedges. The first wedge reflects differences between producer prices and the border (FOB) price, i.e. an export tax or subsidy. The second wedge reflects international trade and transport margins, i.e. the difference between FOB and CIF prices. The third wedge reflects the difference between the CIF price and the end-user price, i.e. import tariffs. All three wedges are fully bilateral.

Model closure is consistent with long-term equilibrium. As stated above, fiscal balance is maintained through lump sum taxes on households under the assumption of fixed public expenditures (relative to GDP). Changes in revenues, for example carbon tax revenues, imply a net decrease in household direct taxes. Investment is savings driven. This assumption implies that changes in investment are likely to be relatively minor since public and foreign savings are fixed and household savings will be relatively stable relative to income. The third closure rule is that the capital account is balanced. Ex ante changes in the trade balance are therefore offset through real exchange rate effects. A positive rise in net transfers, for example through a cap and trade scheme, would tend to lead to a real exchange rate appreciation.

The model dynamics are relatively straightforward. Population and labor force growth rates are based on the UN population's projection ${ }^{7}$ - with the growth in the labor force equated to the growth of the working age population. Investment, as mentioned above, is savings driven and the latter is partially influenced by demographics. Productivity growth

4 The model is designed with several different consumer demand specifications including the CDE (see Hertel 1997), the LES/ELES (see van der Mensbrugghe 2006) and the AIDADS (see Rimmer and Powell 1992 and van der Mensbrugghe 2006). The standard specification is AIDADS.

${ }^{5}$ Armington 1969.

${ }^{6}$ Analogously to aggregate domestic demand, the model allows for a two-nested constant-elasticity-oftransformation function to allocate domestic production between domestic and foreign markets.

7 United Nations 2007. 
in the baseline is 'calibrated' to achieve a target growth path for per capita incomesdifferentiated for agriculture, manufacturing and services.

Emissions of GHGs have three drivers. Most are generated through consumption of goods - either in intermediate of final demand - for example the combustion of fossil fuels. Some are driven by the level of factor input-for example methane produced by rice is linked to the amount of cultivated land. And the remainder is generated by aggregate output - for example waste-based methane emissions. The climate module takes as inputs emissions of GHGs and converts them to atmospheric concentration, then radiative forcing and finally temperature change. ${ }^{8}$ The temperature change is linked back to the socio-economic model through damage functions.

\section{Modelling climate change impacts}

Following Eboli, Parrado and Roson (ibid.), parameters for the impacts are obtained from a number of different sources and specific micro-sectoral studies. The ENVISAGE model is therefore used as a sort of common platform, allowing to assess multiple impacts simultaneously and with a global perspective.

Disaggregated, sectoral climate change impacts have been introduced for the ENVISAGE model by Roson and Sartori (2010). A number of damage functions, one for each type of impact, relate changes in average temperature, by region and year, to changes in a number of parameters and variables of the model. Climate change impacts are therefore introduced as exogenous parameter variations, affecting the general equilibrium in all time steps of the recursive dynamics.

The impacts normally affect exogenous variables, like stocks of land and capital/infrastructure (e.g., in the case of sea level rise), or parameters, like factor or multi-factor productivity (e.g., in the case of agricultural yield). In a few instances, for example for changes in energy demand due to varying needs for cooling/heating, impacts affect naturally endogenous variables, like household energy consumption, through shifting factors in the demand equations.

Most of the relationships are linear, with the notable exception of climate change impacts on agriculture productivity, which are typically positive for small increases in temperature (and concentrations of carbon dioxide in the atmosphere) and negative for larger variations.

Seven types of impacts are considered in this work: agriculture productivity, sea level rise, water availability, tourism, energy demand, human health and labor productivity. Catastrophic events and extreme weather are not taken into account. ${ }^{9}$ In the following, we

\footnotetext{
8 The climate module is largely derived from the MERGE model, Manne et al 1995.

${ }^{9}$ This is due to the lack of reliable estimates, as well as the need of assessing global effects of climate change, rather than the consequences of specific extreme events, limited in time and space. [PAGE/Hope] also uses a Monte Carlo framework that is difficult to emulate with a large dynamic GE model].
} 
briefly describe how each impact has been modelled and how parameters have been estimated.

\section{Agriculture}

Variations in agricultural yield are modelled as changes in multifactor productivity for agricultural activities, so that output volumes are varied when using the same mix of production factors. The relationship between agricultural yield and average temperature is a non-linear one.

Parameters were obtained through elaboration from data presented in the latest IPCC report (Easterling et al., 2007, p. 286), where a meta-analysis can be found, summarizing results from many different studies. Central values for 1, 3 and 5 degrees changes were collected for three crops (maize, wheat, rice) and for high and low latitudes regions, to estimate parameters of a second-degree polynomial. Table 1 summarizes the central estimates for a $3{ }^{\circ} \mathrm{C}$ variation in local mean temperature, under the scenario "with adaptation".

\begin{tabular}{|l|c|c|}
\hline & Mid-High Latitude & Low Latitude \\
\hline Maize & $2 \%$ & $-2 \%$ \\
\hline Wheat & $18 \%$ & $-1 \%$ \\
\hline Rice & $5 \%$ & $1 \%$ \\
\hline
\end{tabular}

Table 1 - Estimates of yield changes for $3^{\circ} \mathrm{C}$ degrees changes in temperature

Region specific parameters for the impact function in this study were obtained through: (1) weighted average of crop functions, with weights given by the relative share of each crop in total agricultural output, as well as by the relative allocation of each region in the two areas (high and low latitudes), and (2) by forcing the function to be zero at zero changes in temperature.

As an example, Figures 1 and 2 show the estimated relationship between temperature changes (in ${ }^{\circ} \mathrm{C}$, with respect to mean temperature in 2000) and average agricultural productivity for USA and China.

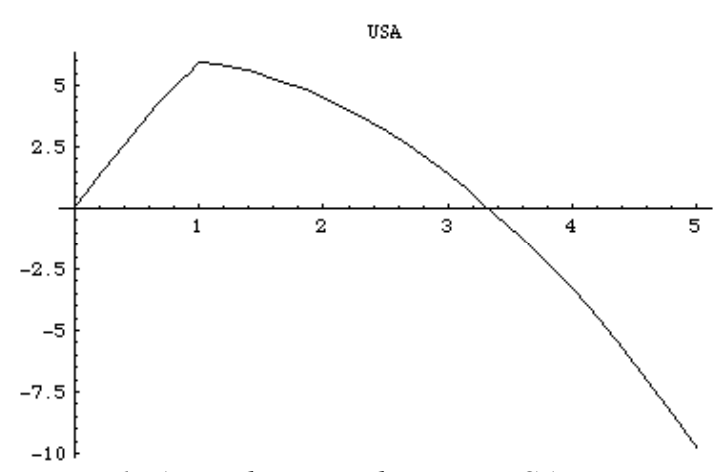

Figure 1. Agriculture productivity USA

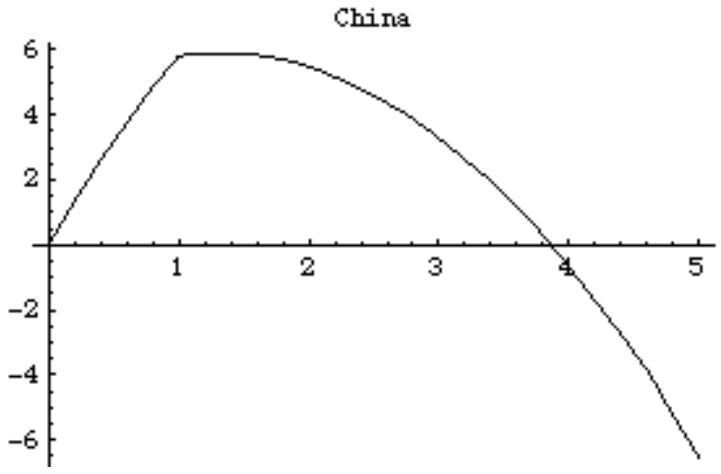

Figure 2. Agriculture productivity China 


\section{Sea Level Rise}

Sea level rise is modelled through reductions in the available stocks of capital and land. Parameters were estimated for a static CGE model (Bosello, Roson and Tol, 2007) from simulation results of the DIVA model (Vafeidis et al., 2008). Parameters for 16 regions in the original CGE model were initially mapped to 10 regions for a specific version of the ENVISAGE model, to conduct preliminary simulation experiments. Subsequently, parameters for all 112 GTAP7 regions have been obtained on the basis of the relative total coast length / total agriculture land ratio.

Although the effects of sea level can be dramatic in some specific areas, the amount of land and capital endowments lost in large regions, like those considered in the present study, is generally limited. Some exceptions are the Rest of East Asia (XEA) region, where about $0.87 \%$ of land and capital stocks are lost for $1{ }^{\circ} \mathrm{C}$ degree increase in temperature, and Rest of South Asia (XSA), where the loss is restricted to $0.35 \%$.

\section{Water}

Water availability affects multifactor productivity (yield) in agriculture. It is assumed that changes in productivity depend on changes in Mean Annual Runoff (MAR) in each country, with effects depending on how much each region is constrained by its water resources. This is estimated on the basis of the current ratio between water demand and available surface water.

This implicitly amounts to assume that: (a) the shares of water resources employed for municipal and industrial uses, as well as for preserving aquatic ecosystems, do not change in the future, (b) there are no changes in water productivity or there is no possibility of substitution between water and other factors in the production processes.

Data for MAR 2000, municipal and industrial demand, environmental flow requirements, and estimates of MAR 2050 according to two different climate GCM models (a simple average of the two scenarios is used here), are taken from Strzepek and Boehlert (2009).

Climate models generally predict a change in the pattern of total precipitation, with more precipitation occurring in temperate and high latitude regions, and less precipitation in lower latitudes. Effects on agricultural productivity depend on how much a certain region is constrained by water resources. For the regional aggregation used in this study, we estimate a strong negative effect of reduced water availability for the Middle East and North Africa (-8.13\% change in agriculture productivity for a one degree increase in temperature) and a positive effect for China (CHN), India (IND), and Sub-Saharan Africa (SSA).

\section{Tourism}

Changes in tourism flows, due to variations in climate conditions, are modelled as adjustments in international income transfers, to account for changes in the expenditure 
of incoming or outgoing tourists. Parameters for tourism have been derived from the Hamburg Tourism Model (Hamilton, Maddison and Tol, 2005). This econometric model estimates changes in tourism flows by country, as a function of several variables, including climate conditions. Average spending for incoming and outcoming tourists have been obtained from the Balance of Payment Statistics (IMF, 2007), by dividing tourism revenue by total tourists in a reference year.

Since income transfers must be globally balanced, the algebraic sum of them is always zero. Positive income transfers are experienced by the United States (becoming, all else equal, a more attractive tourism destination), whereas negative effects are particularly felt in African countries.

\section{Energy Demand}

A model of household energy demand, by fuel type, has been estimated by DeCian, Lanzi and Roson (2007), using econometric techniques and a global panel data base. Energy demand is expressed as dependent, among other factors, on seasonal average temperatures.

By increasing exogenous temperatures, in all seasons, by $1^{\circ} \mathrm{C}$, it is possible to estimate the implied (long-run) change in energy demand, for electricity, gas, and oil products consumption. In ENVISAGE, the corresponding parameter of percentage variation in demand has been estimated as a weighted average of changes in the three fuel components, using data on household consumption from the GTAP7 data base.

For most of the regions, climate change is estimated to reduce the total energy demand by households, as reduced warming needs more than compensate the increased cooling needs. However, some regions do experience an increase in energy demand. These are: Rest of East Asia (XEA), India (IND), Rest of South Asia (XSA) and Brazil (BRA).

\section{Human Health}

Bosello, Roson and Tol (2006) study the economic impacts of climate-change-induced change in human health, viz. cardiovascular and respiratory disorders, diarrhoea, malaria, dengue fever and schistosomiasis. Changes in morbidity and mortality are interpreted as changes in labor productivity and demand for health care, and are used to shock exogenous parameters in a computable general equilibrium model, including 16 regions. The same variations in labor productivity are used here and applied to all countries inside the same macro-region.

Changes can be both positive and negative. Positive variations of labor productivity are expected when climate change reduces the incidence of some, cold-related, diseases. Positive effects are estimated for China (CHN), Russia (RUS), and other regions. Negative and significant effects, however, are estimated for Sub-Saharan Africa (SSA), Middle East and North Africa (MNA), India (IND), Rest of South (XSA) and East (XEA) Asia, United States (USA) and Rest of the World (XLC). 


\section{Labor Productivity}

We consider the ability to work under different climate conditions. Increased temperature and humidity reduce the labor productivity in a number of occupations, requiring open air activity. Kjellstrom et al. (2008) estimate the direct impact of climate change on regional labor productivity. Bosello and Roson elaborated on these results to get estimates of variations in labor productivity for $1^{\circ} \mathrm{C}$ increase in temperature and for 10 macro-regions.

Variations of labor productivity are always negative and especially significant in China (CHN), India (IND) and in most developing countries, where the incidence of agriculture and other open-air activities is relatively larger.

\section{Assessing the effects of climate change on economic growth}

The ENVISAGE model has been first run under exogenous scenarios of GDP growth, ${ }^{10}$ disregarding climate change impacts, or other exogenous shocks. Figure 3 shows the implied evolution of the real GDP, by region, ${ }^{11}$ up to the year 2100 .

\footnotetext{
${ }^{10}$ This is possible by making labor productivity endogenous. The model has also been set to be consistent with current and forecasted energy prices.

${ }^{11}$ Regional acronyms as follows: $\mathrm{CHN}=\mathrm{China}, \mathrm{JPN}=\mathrm{Japan}, \mathrm{XEA}=$ Rest of East Asia, IND=India, $\mathrm{XSA}=$ Rest of South Asia, USA=United States, BRA=Brazil, RUS=Russia, XEC=Rest of Eastern Europe and Central Asia, SSA=Sub-Saharan Africa, EUR=Europe, MNA=Middle East and North Africa, rha=Rest of high income countries (Kyoto Protocol Annex I), rhy=Rest of HIC (non ANNEX I), xlc=Rest of the World.
} 


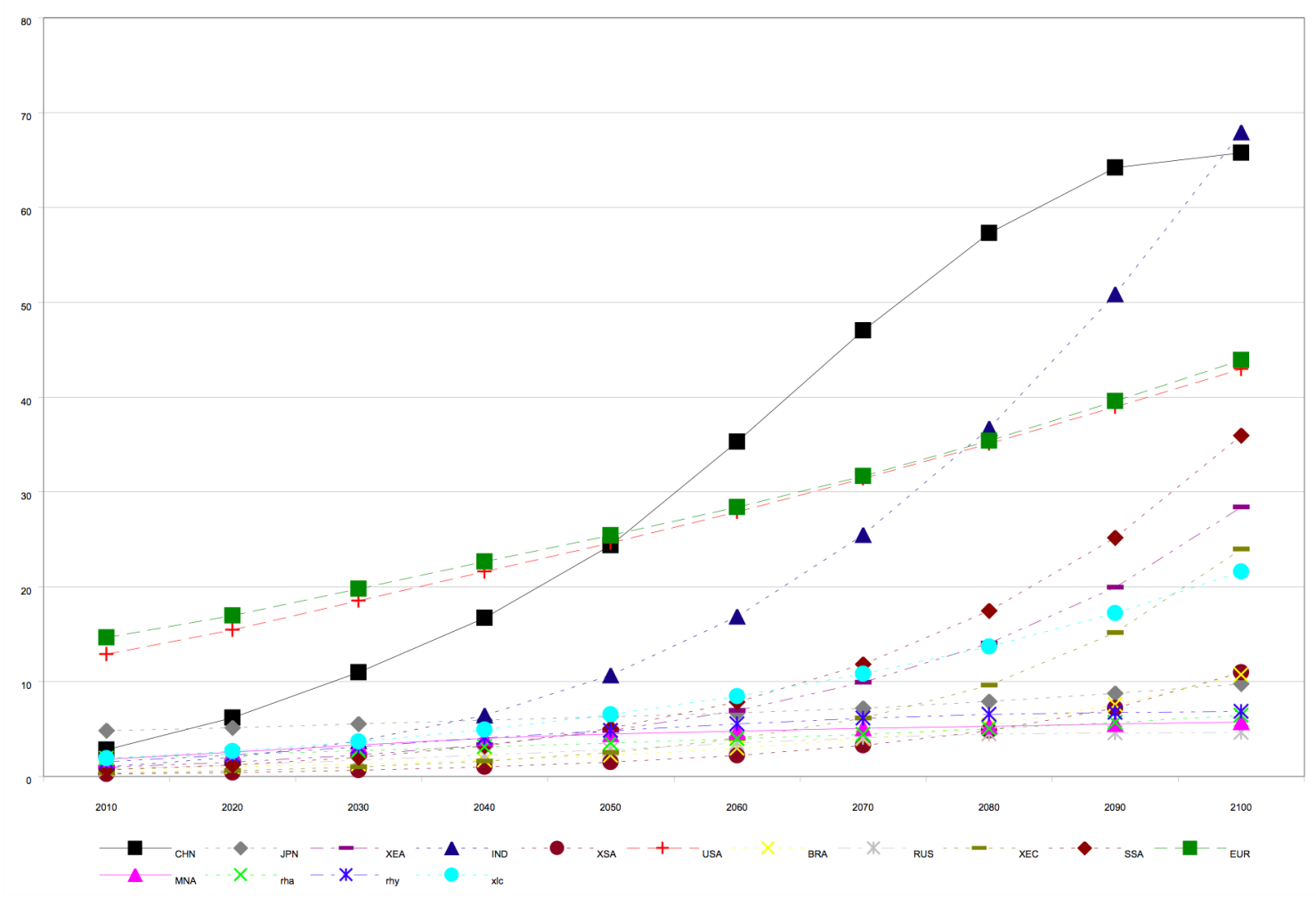

Figure 3 -Benchmark growth path for regional GDP 2010-2100

As can be seen, United States and Europe are assumed to grow at a steady rate, with China first and later India catching up and leapfrogging them in terms of total GDP. Some others regions also exhibit a tendency towards income convergence, although the tendency is not a general one.

ENVISAGE includes a climate module, therefore temperature changes are estimated consistently with economic growth. Figure 4 shows the simulated evolution of average world temperature with respect to the year 2000, with and without the influence of climate change impacts. The impacts tend to slow the global economy, therefore GHG emissions and concentrations. However, because of the strong inertia of the system, the differences between the two scenarios are minimal. 


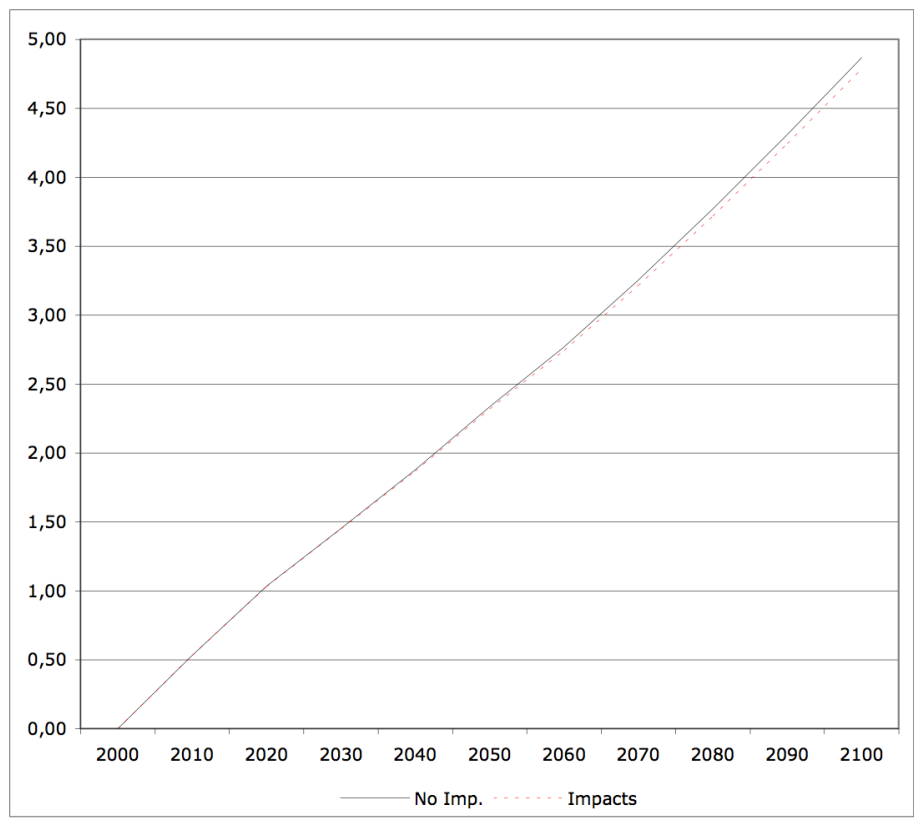

Figure 4 - Increase of world average temperature w.r.t. 2000

The global average temperature is found to change in the $21^{\text {st }}$ century by $4.87^{\circ} \mathrm{C}$, reduced to $4.79^{\circ} \mathrm{C}$ when climate impact feedbacks are taken into account. This figure is quite high if compared with those of the IPCC SRES scenarios $\left(1.79{ }^{\circ} \mathrm{C}\right.$ for $\mathrm{B} 1,2.65{ }^{\circ} \mathrm{C}$ for A1B, $3.13{ }^{\circ} \mathrm{C}$ for $\mathrm{A} 2$ ), but consistent with the (upward revised) recent estimates of the MIT Integrated Global Systems Model, predicting an increase of $5.2{ }^{\circ} \mathrm{C}$ with respect to preindustrial temperature. $^{12}$

When climate change impacts are simulated, ENVISAGE produces new estimates for income and consumption levels, industrial production volumes, trade flows, prices and many other variables (including climatic ones). It is therefore interesting to see how much these new estimates deviate from those of the baseline scenario, to get an assessment of the economic consequences of climate change impacts.

Figure 5 shows percentage deviation of real GDP, at 10-years intervals, for all regions in the model. The results confirm that the effects are significant and the most negative consequences are felt in developing, relatively poorer, countries. Potential real GDP is brought down by as much as $-12.6 \%$ for "Rest of East Asia" and $-10.3 \%$ for "Middle East and North Africa", by the end of the century. Only a few regions gain (RUS, EUR, JPN, rha), but relatively little (Russia $+2.4 \%$, Europe $+1.2 \%$ ).

\footnotetext{
${ }^{12} \mathrm{http}: / /$ globalchange.mit.edu/igsm/
} 


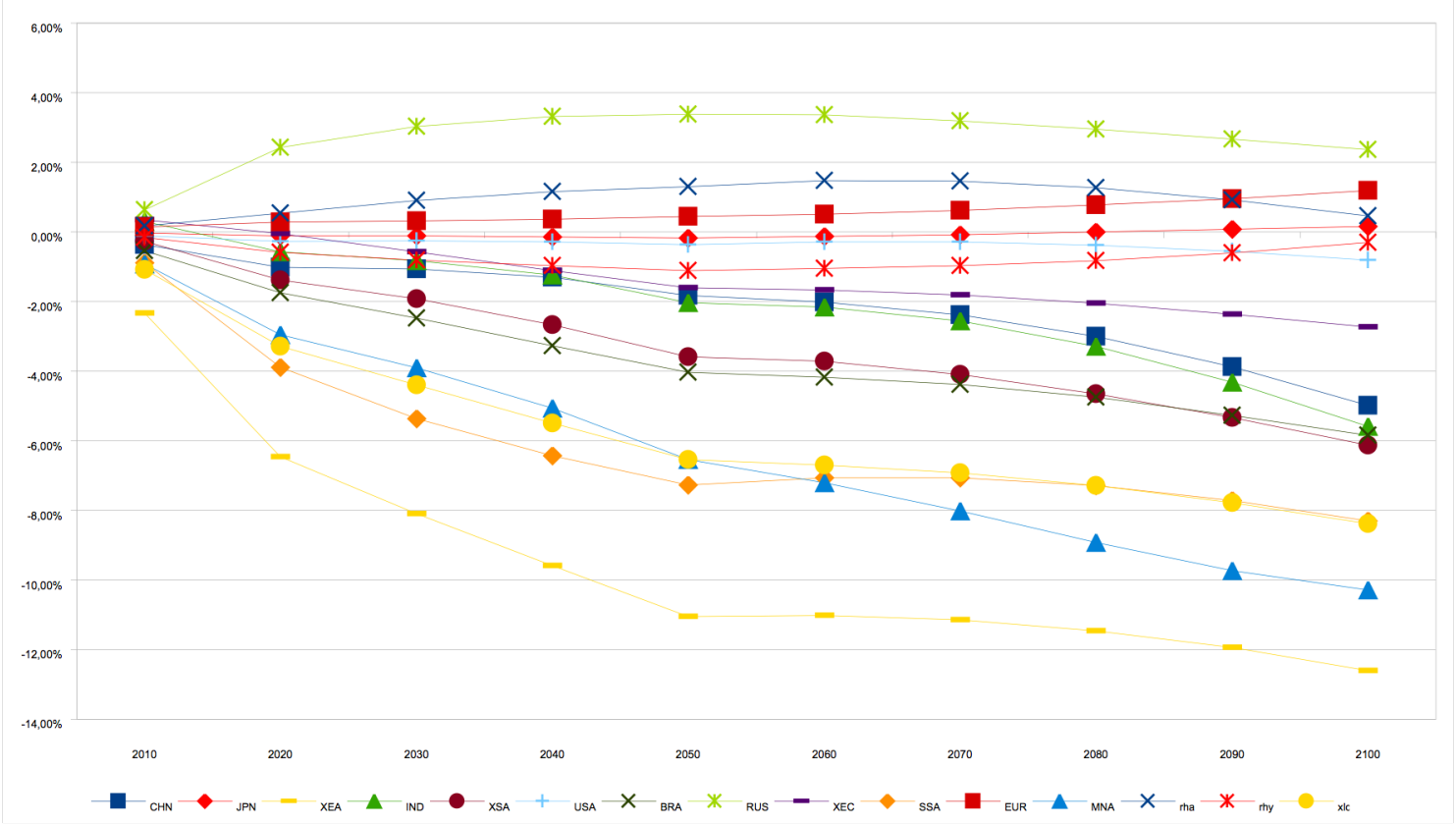

Figure 5 -Deviations of regional GDP from the baseline 2010-2100

In order to better understand the contribution of each possible climate impact to the overall result, it is possible to run the ENVISAGE model with only some impacts active at a time. Figure 6 shows the decomposition of the effects for the year 2100 .

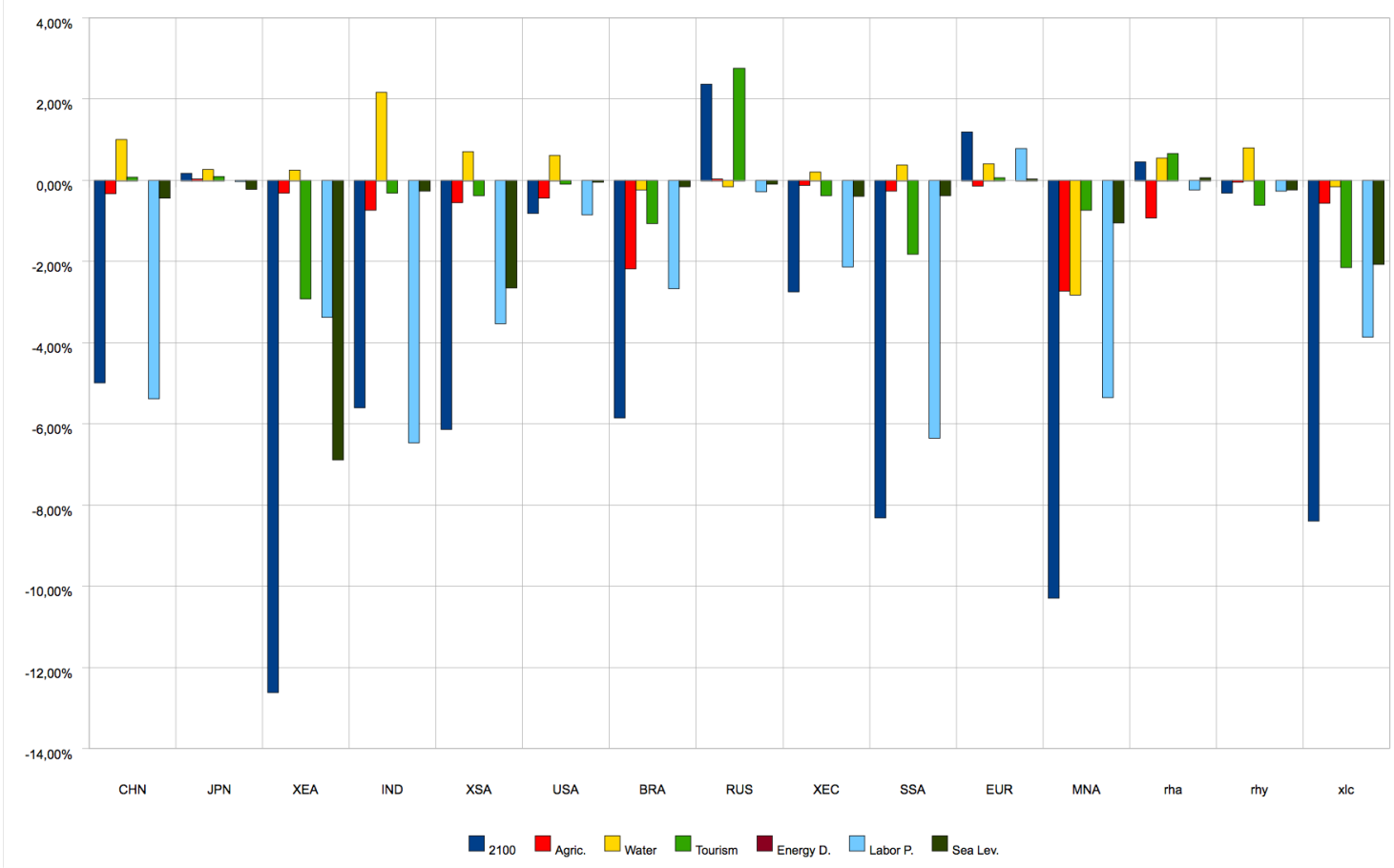

Figure 6 - Decomposition of real GDP deviations in terms of impact contribution 
The first blue bar corresponds to the last point in Figure 5, whereas the other bars shows the effect on real GDP of a specific impact category. ${ }^{13}$ For the two biggest losers, we see that the origin of the problems is different. Much of the loss in East Asia is due to sea level rise, whereas for Middle East and North Africa the loss is driven by a drop in labor productivity (combined effect of human health and on the job productivity), followed by water scarcity, affecting productivity in agriculture. We can also see that almost all the gain experienced by Russia is due to tourism, as countries in higher latitudes become more attractive travel destinations.

Results like those illustrated above can be produced by the ENVISAGE model for many other variables. Perhaps it is interesting to see what the effects are on disposable household income, which could be considered a gross index of welfare. Figure 7 is the analogous of Figure 5 for the disposable income variable.

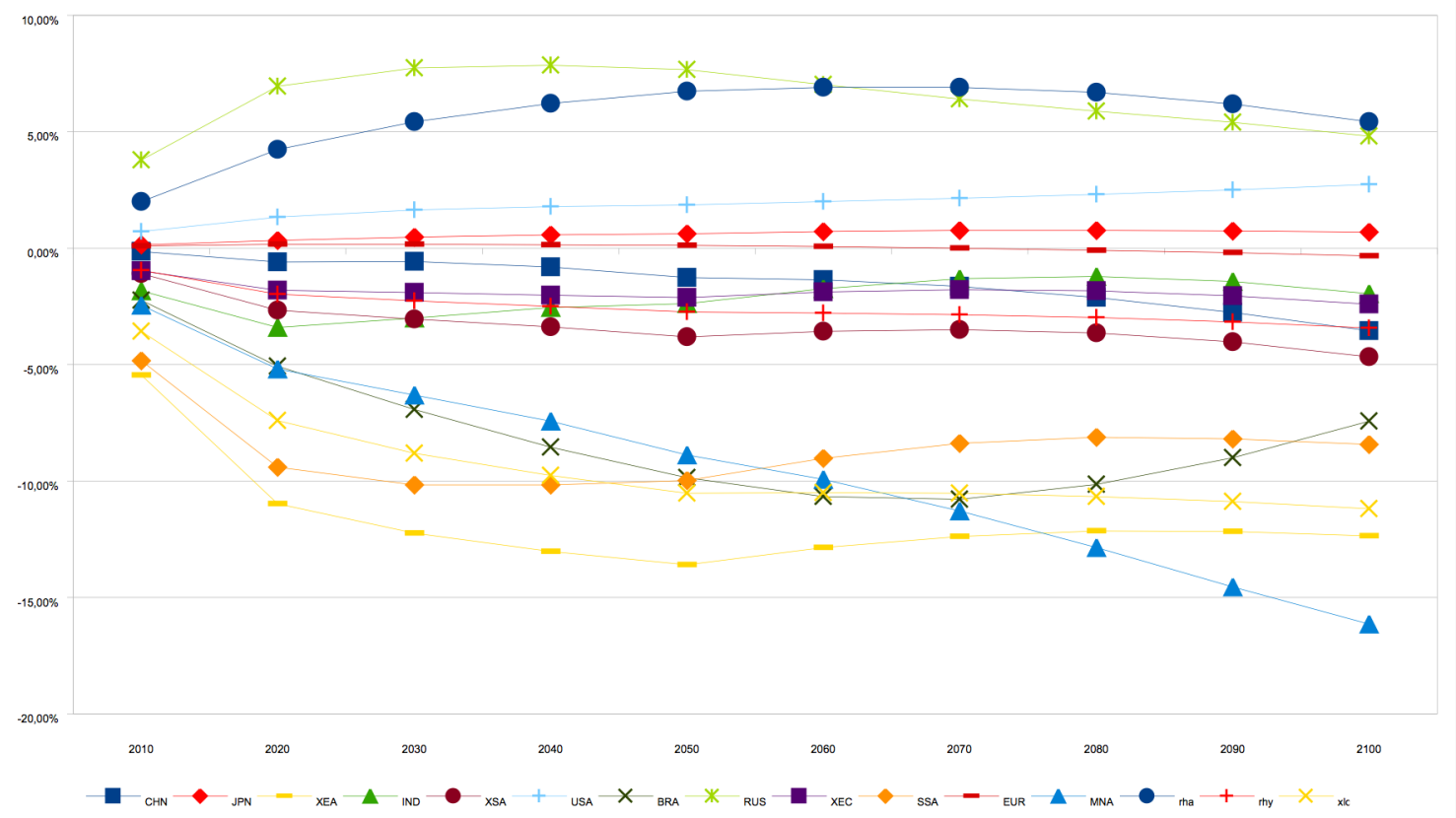

Figure 7 - Deviations of regional HH income from the baseline 2010-2100

The global picture does not change very much, but variations are larger and the ranking among the different regions is also different. Welfare effects on the MNA region are much worse $(-16.14 \%$ at 2100$)$. It may be shown that the main factor here is water scarcity. Household income in Europe slight decreases, although there is a gain in real GDP.

The model can compute variations in emissions due to the climate change feedback. Figure 8 shows the reduction in emissions for carbon dioxide $\left(\mathrm{CO}_{2}\right)$, methane $\left(\mathrm{CH}_{4}\right)$, nitrous oxide $\left(\mathrm{N}_{2} \mathrm{O}\right)$ and fluorocarbons (F-GAS).

\footnotetext{
${ }^{13}$ Because of general equilibrium effects, single impact results do not sum up to the global total.
} 


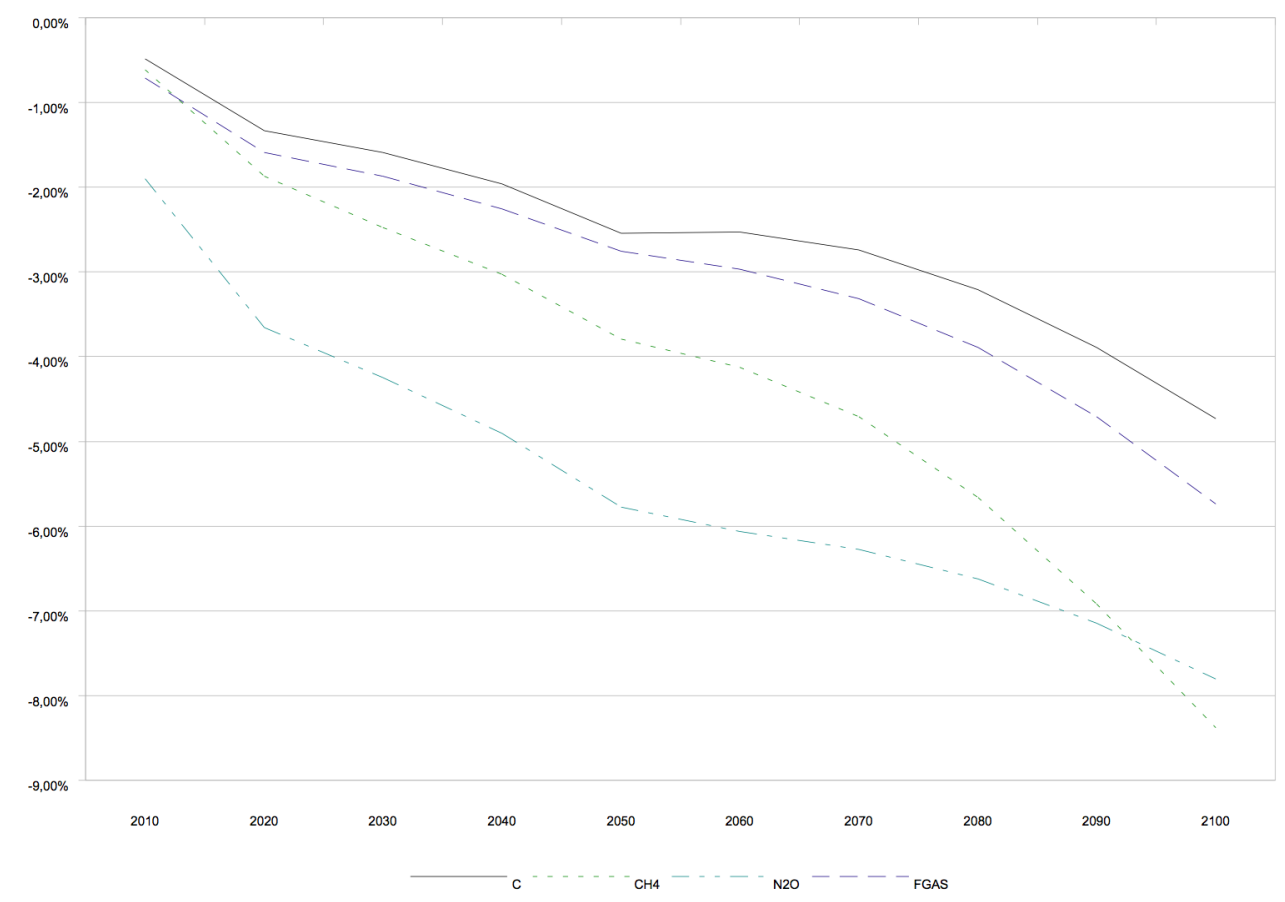

Figure 8 -Percentage reduction in global emissions due to climate feedback

Changes are not negligible. For example, climate change impacts imply an automatic reduction of $\mathrm{CO}_{2}$ emissions worldwide by $-4.7 \%$ in 2100 , whereas changes for methane are $-8.4 \%$ and for $\mathrm{N}_{2} \mathrm{O}$ are $-7.8 \%$. Of course, variations in atmospheric concentrations are not that large, and the effect on temperature is even smaller, at least in the short run.

\section{Concluding remarks}

The IPCC's Third Assessment Report was a sobering reminder of the potential and damaging consequences of anthropogenic emissions and their association with climate change. The time frame, however, suggested that though there was urgency to act on the mitigation side, due to the inherent inertia in both the economic and climate systems, there was less urgency about the timing of the negative impacts. An extra decade of evidence, including that contained in the 2007 IPCC Fourth Assessment Report, has balanced this sense of urgency and has put the adverse impacts from climate change at the forefront of the discussion, particularly as it affects the poorest and more vulnerable economies. Moreover, as this paper and others describe, the global economy is on a much higher growth and emissions path than the scenarios of the late 1990s, which has formed the basis of much of the empirical work over the last decade - thus if anything, we would anticipate an acceleration of climate change impacts.

This paper attempts to collate the available micro evidence of the climate change impacts through its most important economic channels - agricultural productivity, water stress, climate induced changes to labor productivity, health and energy impacts and loss of land 
and infrastructure from rising sea levels. These impacts are highly variegated across regions and source of the impact. According to our preliminary estimates, at the global level, the most serious consequence from climate change will be changes to labor productivity that would induce $84 \%$ of the global damage in 2050 (-1.8\% of global GDP) and $76 \%$ in 2100 (-4.6\% of global GDP). The labor productivity impacts account for both human health effects and direct lower productivity in hot and humid conditions. The most seriously impacted region in 2100 is the Middle East and North Africa, followed closely by East Asia - the former suffering mostly from direct hits to labor productivity and the latter more from sea-level rise. The impacts on agriculture in the medium term, to around 2050 , are not particularly dire (with the caveat that we are ignoring by and large extreme events), but as temperatures rise further, the negative impacts kick in and overtime will be quite harsh (causing a loss of potential GDP larger than $2 \%$ in Brazil, Middle East and North Africa). Another impact which is producing relevant consequences in the one on tourism. Since a different climate will affect tourists' destination choices, this will create a different pattern of tourism flows, with limited effects at the global level but potentially serious implications at the regional level. Overall, tourism impacts are expected to worsen the distributional consequences of climate change, with losses for most developing countries and some gains for developed regions located at high latitudes.

These results should be seen as very preliminary. First, the empirical results are not as detailed as one would desire. For example, in agriculture, the damage parameters are being derived from only three crops and with two spatial data points. Work is ongoing on a broader regional and sectoral basis to derive more detailed estimates. Similar issues arise for the impacts. Second, there is a degree of uncertainty associated with much of the empirical evidence - for example the role of carbon fertilization, uncertainty about the spatial downscaling of the climate models (particularly as regards water availability). This suggests a greater need for sensitivity analysis - be it systematic (relatively easy) or Monte Carlo-type (computer intensive). Third, the impacts as described herein are continuous, and if properly anticipated, many could be handled at relatively low cost through appropriate adaptation. More difficult to deal with (the 'unknown unknowns') are catastrophic or higher frequencies of extreme events. These in the end could lead to dis-continuous changes and much higher costs.

\section{Acknowledgements}

We gratefully acknowledge the essential assistance of Jianwu He and Martina Sartori. 


\section{References}

Armington, P. (1969), "A Theory of Demand for Products Distinguished by Place of Production," IMF Staff Papers, Vol. 16, pp. 159-178.

Berrittella, M., A.Bigano, R. Roson and R.S.J. Tol (2006), “A General Equilibrium Analysis of Climate Change Impacts on Tourism", Tourism Management, vol.25(5), pp. 913-924.

Bosello, F., R. Roson and R.S.J. Tol (2006), "Economy wide estimates of the implications of climate change: human health", Ecological Economics, vol. 58, pp. $579-591$.

Bosello, F., R. Roson and R.S.J. Tol (2007), "Economy wide estimates of the implications of climate change: sea level rise", Environmental and Resource Economics, vol. 37, pp. 549-571.

De Cian, E., Lanzi, E. and R. Roson (2007), The Impact of Temperature Change on Energy Demand: A Dynamic Panel Analysis, FEEM Working Paper N.46.2007.

Deke, O., K. G. Hooss, C. Kasten, G. Klepper and K. Springer (2001), Economic Impact of Climate Change: Simulations with a Regionalized Climate-Economy Model, Kiel Working Papers 1065, Kiel Institute for the World Economy.

Dell, M., Jones, B.F., and Olken, B.A. (2008), Climate Change and Economic Growth: Evidence from the Last Half Century, National Bureau of Economic Research working paper 14132 .

Easterling, W.E., P.K. Aggarwal, P. Batima, K.M. Brander, L. Erda, S.M. Howden, A. Kirilenko, J. Morton, J.-F. Soussana, J. Schmidhuber and F.N. Tubiello, (2007), "Food, fibre and forest products. Climate Change 2007: Impacts, Adaptation and Vulnerability. Contribution of Working Group II to the Fourth Assessment Report of the Intergovernmental Panel on Climate", in: Change, M.L. Parry, O.F. Canziani, J.P. Palutikof, P.J. van der Linden and C.E. Hanson, Eds., Cambridge University Press, Cambridge, UK, 273-313.

Eboli, F., Parrado, R. and Roberto Roson (2009), Climate Change Feedback on Economic Growth: Explorations with a Dynamic General Equilibrium Model, Working Paper 2009.43, Fondazione Eni Enrico Mattei.

Hamilton J.M. , Maddison D.J. and Tol R.S.J (2005), "Effects of climate change on international tourism", Climate Research, 29, pp. 245-254.

Hertel, Thomas W., editor (1997), Global Trade Analysis: Modeling and Applications, Cambridge University Press, New York. 
Kiellstrom T., R.S. Kovats, S.J. Lloyd, T. Holt, R.S.J. Tol (2008), The direct impact of climate change on regional labor productivity, ENSEMBLES Deliverable D7.8, European Commission, VI Framework Programme.

Manne, Alan, Robert Mendelsohn and Richard Richels (1995), "MERGE: A model for evaluating regional and global effects of GHG reduction policies," Energy Policy, 23(1), pp. 17-34.

Rimmer, M. T. and A. A. Powell (1992), An Implicitly Directly Additive Demand System: Estimates for Australia, Impact Project Preliminary Working Paper No. OP-73.

Roson, R. and M. Sartori (2010), The ENVIRONMENTAL IMPACT AND SUSTAINABILITY APPLIED GENERAL EQUILIBRIUM (ENVISAGE) Model. Introducing Climate Changes Impacts and Adaptation. Changes in the Model Structure and Parameters' Estimation, Mimeo, the World Bank.

Stern, N. (2007), The Economics of Climate Change - the Stern Review, Cambridge University Press.

Strzepek, K. and B. Boehlert (2009), Competition for Water for the Food System, Mimeo.

United Nations (2007), World Population Prospects: The 2006 Revision Population Database, United Nations Population Division, New York, NY, http://esa.un.org/unpp/.

Vafeidis A. T., R. J. Nicholls, L. McFadden, R. S. J. Tol, J. Hinkel, T. Spencer, P. S. Grashoff, G. Boot, R. J. T. Klein (2008), A New Global Coastal Database for Impact and Vulnerability Analysis to Sea-Level Rise, Journal of Coastal Research, 24(4), pp. 917-924.

van der Mensbrugghe, D. (2006), Linkage Technical Reference Document, Mimeo, The World Bank.

van der Mensbrugghe, D. (2008), The ENVIRONMENTAL IMPACT AND $\underline{S}$ USTAINABILITY APPLIED GENERAL EQUILIBRIUM (ENVISAGE) Model, Mimeo, the World Bank. 